\title{
Robotic intercostal nerve harvest: a feasibility study in a pig model
}

\author{
Hideaki Miyamoto, MD,,2 Thomas Serradori, MD, ${ }^{3}$ Yoji Mikami, MD, PhD, ${ }^{4}$ Jesse Selber, MD, ${ }^{5}$ \\ Nicola Santelmo, MD, ${ }^{6}$ Sybille Facca, MD, PhD, ${ }^{1}$ and Philippe Liverneaux, MD, PhD ${ }^{1}$

\begin{abstract}
1Department of Hand Surgery, University Hospital of Strasbourg, FMTS, Illkirch, France; 2Department of Orthopaedic Surgery, University of Tokyo, Tokyo, Japan; ${ }^{3}$ General and Digestive Department, University Hospital of Nancy, Nancy, France; ${ }^{4}$ Department of Orthopaedic Surgery, Yokohama Rosai Hospital, Yokohama, Japan; ${ }^{M}$ MD Anderson Center, Houston, Texas; and ${ }^{6}$ Department of Thoracic Surgery, University Hospital of Strasbourg, FMTS, Strasbourg, France
\end{abstract}

The aim of this study was to report the feasibility of robotic intercostal nerve harvest in a pig model. A surgical robot, the da Vinci Model S system, was installed after the creation of 3 ports in the pig's left chest. The posterior edges of the fourth, fifth, and sixth intercostal nerves were isolated at the level of the anterior axillary line. The anterior edges of the nerves were transected at the rib cartilage zone. Three intercostal nerve harvesting procedures, requiring an average of 33 minutes, were successfully performed in 3 pigs without major complications.

The advantages of robotic microsurgery for intercostal nerve harvest include elimination of physiological tremor, free movement of joint-equipped robotic arms, and amplification of the surgeon's hand motion by as much as 5 times. Robotassisted neurolysis may be clinically useful for intercostal nerve harvest for brachial plexus reconstruction.

http://thejns.org/doi/abs/10.3171/2015.1.JNS14603

KEY WORDS brachial plexus; da Vinci robot; intercostal nerve; robotic microsurgery; telemicrosurgery; surgical technique

$\mathrm{I}$ NTERCOSTAL nerves are commonly used as donor nerves for brachial plexus reconstruction. ${ }^{30}$ Harvesting of intercostal nerves by a conventional open approach requires a large surgical exposure, which can lead to perioperative complications..$^{10}$ In developing minimally invasive techniques, Mikami et al. have described clinical cases in which video-assisted thoracoscopy with small incisions was used to transfer intercostal nerve segments to the musculocutaneous nerve. ${ }^{4,18}$ Thoracoscopic intercostal nerve harvest, however, still presents difficulties because of the long duration of surgery and also because endoscopic instruments are not capable of sufficiently fine movement and interfere with surgeon precision.

Recently, the development of robotics has allowed a glimpse into new perspectives in microsurgery. ${ }^{6,13,16,23,31}$ Surgical robots have some properties that are well adapted to microsurgery, such as $3 \mathrm{D}$ vision magnified up to 25 times, movements of the surgeon enhanced up to 5 times, 7 degrees of wrist articulation, elimination of physiological tremor, and ergonomic surgical positioning. ${ }^{12}$ The microsurgical and endoscopic properties of robotic systems have already demonstrated feasibility in thoracic surgery and have been used to perform sympathectomy, ${ }^{5}$ thymectomy, ${ }^{17,29}$ and esophagectomy ${ }^{36}$ via a thoracoscopic approach.

The aim of the current study is to report the feasibility of robotic intercostal nerve harvest in a pig model.

\section{Methods}

This animal study was approved and conducted according to the French government guidelines on animal care and use. Three domestic female swine (sus scrofa domesticus), having an average weight of $30 \mathrm{~kg}$, were anesthetized using a ketamine $(10 \mathrm{mg} / \mathrm{kg}) /$ midazolam $(0.1 \mathrm{mg} / \mathrm{kg})$ solution, followed by maintenance on pentothal $(10 \mathrm{mg} / \mathrm{kg} / \mathrm{hr})$. The pigs were intubated, and double-lung ventilation was maintained. After induction of general anesthesia, the pigs were placed in the right lateral decubitus position. 
We have designed the robotic intercostal nerve harvest procedure in 3 stages: setup of the robot, approaches with 3 ports, and intercostal nerve dissection. The da Vinci surgical robot (Model S, Intuitive Surgical, Inc.) was set up (Fig. 1). We placed 3 ports, each $2 \mathrm{~cm}$ in diameter, in the left side of the pig's chest (Fig. 2). The camera allowed $3 \mathrm{D}$ vision and progressive magnification up to $\times 25$. The movements of the instruments were multiplied by 5 times (superfine position). After the video camera was introduced into the first port, forceps and scissors were introduced under direct vision (Fig. 3A). The video camera arm was equipped with a carbon dioxide insufflation system at a pressure of $4 \mathrm{~mm} \mathrm{Hg}$ to maintain the operative field and control bleeding. The posterior edges of the fourth, fifth, and sixth intercostal nerves were isolated by microsurgical forceps, microscissors, and a hydrodissector (Erbejet) to the anterior axillary line (Fig. 3B). Venous bleeding was coagulated (Fig. 3C). The anterior edges of the 3 intercostal nerves were transected using robotic microscissors at the rib cartilage zone (Fig. 3D).

An assistant thoracic surgeon arranged the setting and replacement of robotic arms. All robotic intercostal nerve harvests were performed (Video 1) by the same microsurgeon.

VIDEO 1. Clip showing steps in robotic intercostal nerve harvest in a pig model. Copyright Philippe Liverneaux. Published with permission. Click here to view with Media Player. Click here to view with Quicktime.

\section{Results}

The time to set up the robot and place the 3 ports averaged 33 minutes (40, 30, and 30 minutes). The surgical time for harvesting the fourth, fifth, and sixth intercostal nerves in the console averaged 40 minutes $(45,35$, and 40 minutes). The total time needed for the procedure was 1 hour and 13 minutes. The intercostal nerve harvests were successfully performed under appropriate carbon dioxide insufflation without having to convert the procedures to

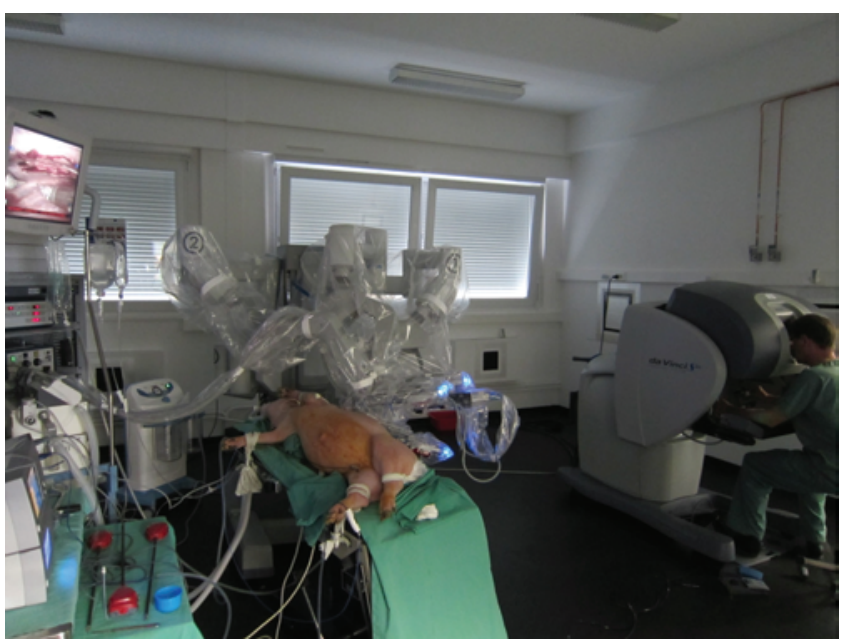

FIG. 1. Photograph showing a pig placed in the lateral decubitus position and prepared for robotic intercostal nerve harvest. The robot is placed above the pig's shoulder. The visualization system is in front of the animal and the surgeon console is behind it. Figure is available in color online only.

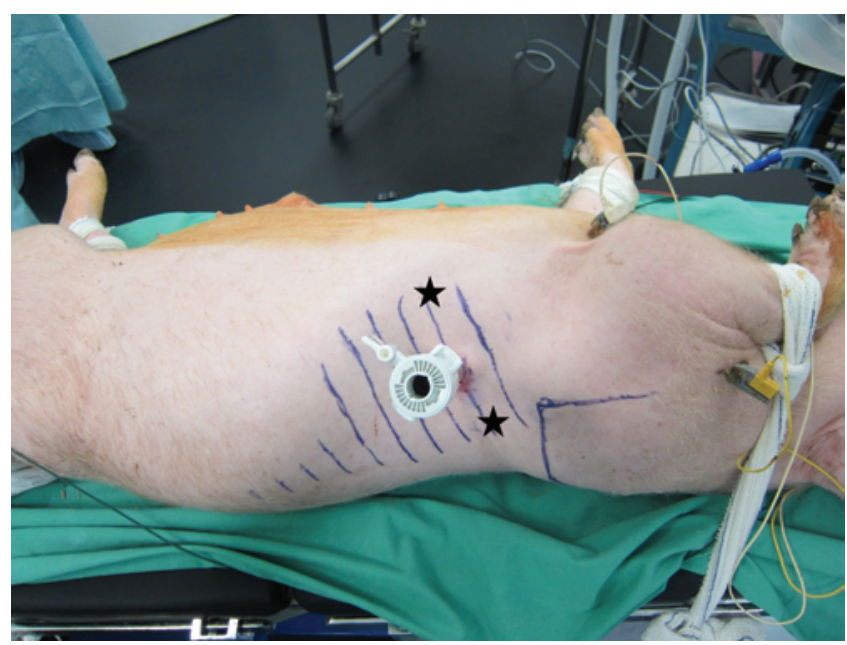

FIG. 2. Skin is marked to show the location of ports for the robotic arms. The first port was placed in the sixth intercostal space in the midaxillary line for the video camera arm (cannula); the second and third ports were placed $5 \mathrm{~cm}$ anterior and posterior to the first port at the level of the seventh intercostal space (stars). These two ports were used for robotic arms. Figure is available in color online only.

the conventional open approach. The ribs and major intrathoracic organs appeared intact. No intercostal nerve was accidentally transected. The total amount of bleeding during the operation averaged less than $20 \mathrm{ml}$.

\section{Discussion}

Refinement of open intercostal nerve transfer procedures and the development of advanced microsurgical techniques for restoration of elbow flexion following brachial plexus injuries have improved the outcomes of nerve transplantation procedures. ${ }^{11,15,22,24,34}$ The drawbacks of the conventional open approach for harvesting intercostal nerves include relatively long skin incisions, ${ }^{34}$ undesirable pleural damage,${ }^{10}$ wound infection, ${ }^{10}$ and thoracic cage deformity. ${ }^{26}$ Complication rates increase as the number of intercostal nerves harvested increases..$^{10}$ Kawabata et al. investigated mild growth retardation of ribs corresponding to the site of donor intercostal nerves, although no thoracic cage deformity was detected clinically. ${ }^{9}$ Leaving the periosteum of the ribs intact during dissection of the intercostal nerves is crucial if thoracic cage deformity is to be avoided. ${ }^{26}$

To resolve these drawbacks, the intercostal nerve harvesting process has been advanced using video-assisted thoracoscopy. ${ }^{2,19,21}$ In 2006, Mikami et al. successfully performed 12 intercostal nerve neurolysis procedures in 3 mini-pig models. ${ }^{11,19}$ One of 12 nerves was inadvertently transected during neurolysis. The average time for nerve harvesting was 30-60 minutes for each nerve., ${ }^{2,19}$ In 3 clinical cases described by Mikami and colleagues in 2008, ${ }^{20}$ 4 thoracoscopic ports for harvesting 2 intercostal nerves were used. All patients recovered useful biceps function (Medical Research Council Grade 3+/5). One of these 3 clinical cases had to be converted to a conventional open nerve harvesting procedure due to accidental nerve transection. The total operation time in the first clinical case was 9 hours. ${ }^{20}$ Video-assisted thoracic surgery was also 

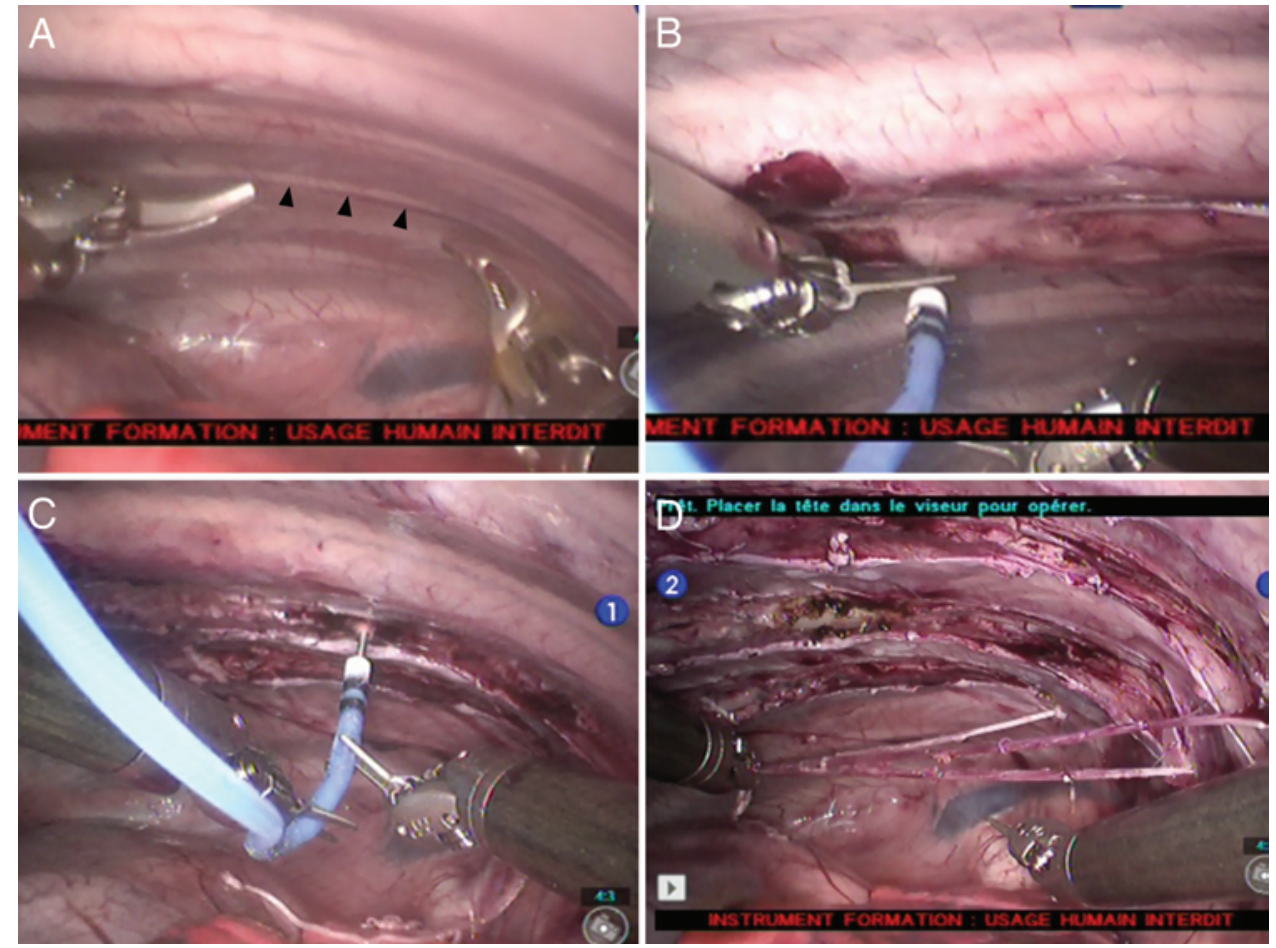

FIG. 3. Views of the operative field. The fourth intercostal nerve was identified through the pleura along the caudal margin of the rib (arrowheads). A: After the video camera was introduced into the first port, forceps and scissors were introduced under direct vision. B: The posterior edge of the intercostal nerve was isolated by microsurgical forceps and then by the water-jetting tool held in a forceps. C: Coagulation of venous bleeding using the coagulation wire of the Erbejet. D: The 3 harvested intercostal nerves. Figure is available in color online only.

applied to harvesting a full-length phrenic nerve to allow direct nerve transfer to the biceps. ${ }^{37}$ Although existing endoscopic instruments are available for harvesting intercostal nerves, there are some incompatibilities related to the instruments' size and the restricted maneuverability of the tips of the instruments. ${ }^{20}$

The most important advantages of robotic microsurgery (telemicrosurgery) for intercostal nerve harvest are motion scaling up to 5 times, elimination of physiologic tremor, and free movement of joint-equipped robotic arms, which can improve manipulation. ${ }^{12}$ Several publications have compared surgeon performance using robotic microsurgery to conventional freehand microsurgery. Results were similar in the repair of anastomosis: operative time was shorter with conventional freehand microsurgery, ${ }^{8,28}$ but surgery-related comfort was superior with the telemanipulator. The surgical robot has been applied in 3 different types of procedure: 1) brachial plexus reconstruction using the Oberlin procedure, ${ }^{23} 2$ ) nerve transfer to the deltoid muscle using the nerve to the long head of the triceps; $; 2$ and 3) supraclavicular brachial plexus procedures. ${ }^{16}$ As with other reported robot-assisted thoracic surgeries, ${ }^{1,14,17}$ robotic intercostal nerve harvesting may contribute to postoperative pain reduction, shorter hospitalization, earlier return to usual activities, lower complication rates, and better quality of life outcomes. After harvesting by robot-assisted thoracoscopy, intercostal nerves can be directed to the axilla subcutaneously and can be anastomosed to whichever nerve is needed to reanimate a particular muscle (biceps, triceps, etc.). Based on 3 clinical cases of ours, the length of harvested nerve allows direct repair of the recipient nerve (an interpositional graft is not required).

Potential complications associated with robotic intercostal nerve harvest include pneumothorax, atelectasis due to single-lung ventilation, and iatrogenic intrathoracic injuries. Most of the current literature on postoperative respiratory complications after intercostal nerve harvest showed minimal or no clinical effect on respiratory function. ${ }^{3,11,35}$ Chalidapong et al. reported that objective pulmonary function was reduced for 2 weeks and normalized within 3 months. Single-lung ventilation has usually been suggested for video-assisted thoracoscopic surgery to retain the working field and facilitate the surgery. Some authors have investigated the use of double-lung ventilation in thoracoscopic surgery and found that it was safe and provided appropriate exposure while decreasing cost, operative time, and undesirable complications in comparison with single-lung ventilation. ${ }^{7,32,34}$ Our procedure requires a chest tube, unlike the open technique, which, although taking more time and requiring a larger incision, rarely needs a chest tube. Another disadvantage of robotics, which must be weighed against its benefits, is the cost of acquisition, maintenance, and operation of the system.

In our animal experiment, we were able to establish an adequate surgical view and working field under doublelung ventilation. The absence of sensory feedback has been criticized as a fault of surgical robots. ${ }^{33}$ However, sensory feedback is not mandatory in conventional microsurgical procedures. ${ }^{25}$ We had no difficulty in using the robot to 
harvest the intercostals nerves without sensory feedback. For clinical cases, to avoid iatrogenic intrathoracic injuries, the surgeon must perform the robotic-assisted nerve harvest under supervision by an experienced thoracic surgeon and be prepared to convert to the conventional open procedure.

\section{Conclusions}

Three intercostal nerve harvests in 3 pigs each were performed using a robot. We conclude that intercostal nerve harvest in an animal model is feasible using the surgical robot. Robot-assisted neurolysis appears to be safe and may be useful for intercostal nerve harvest in clinical cases for brachial plexus reconstruction.

\section{References}

1. Balduyck B, Hendriks JM, Lauwers P, Mercelis R, Ten Broecke P, Van Schil P: Quality of life after anterior mediastinal mass resection: a prospective study comparing open with robotic-assisted thoracoscopic resection. Eur J Cardiothorac Surg 39:543-548, 2011

2. Cáceres JP, Palazzi S, Palazzi JL, Llusá M, M S, S V: Dissection of intercostal nerves by means of assisted video thoracoscopy: experimental study. J Brachial Plex Peripher Nerve Inj 8:3, 2013

3. Chalidapong P, Sananpanich K, Kraisarin J, Bumroongkit C: Pulmonary and biceps function after intercostal and phrenic nerve transfer for brachial plexus injuries. J Hand Surg [Br] 29:8-11, 2004

4. Chuang DC, Yeh MC, Wei FC: Intercostal nerve transfer of the musculocutaneous nerve in avulsed brachial plexus injuries: evaluation of 66 patients. J Hand Surg Am 17:822828,1992

5. Coveliers H, Meyer M, Gharagozloo F, Wisselink W, Rauwerda J, Margolis M, et al: Robotic selective postganglionic thoracic sympathectomy for the treatment of hyperhidrosis. Ann Thorac Surg 95:269-274, 2013

6. Garcia JC Jr, Mantovani G, Gouzou S, Liverneaux P: Telerobotic anterior translocation of the ulnar nerve. J Robot Surg 5:153-156, 2011

7. Javid MJ, Toolabi K, Aminian A: Two lung ventilation through single lumen tracheal tube in thoracoscopic thymectomy: a randomized clinical trial of efficacy and safety. Middle East J Anaesthesiol 19:1361-1368, 2008

8. Karamanoukian RL, Bui T, McConnell MP, Evans GR, Karamanoukian HL: Transfer of training in robotic-assisted microvascular surgery. Ann Plast Surg 57:662-665, 2006

9. Kawabata H, Shibata T, Matsui Y, Yasui N: Use of intercostal nerves for neurotization of the musculocutaneous nerve in infants with birth-related brachial plexus palsy. J Neurosurg 94:386-391, 2001

10. Kovachevich R, Kircher MF, Wood CM, Spinner RJ, Bishop AT, Shin AY: Complications of intercostal nerve transfer for brachial plexus reconstruction. J Hand Surg Am 35:19952000, 2010

11. Krakauer JD, Wood MB: Intercostal nerve transfer for brachial plexopathy. J Hand Surg Am 19:829-835, 1994

12. Liverneaux P, Berner SH, Bednar MS, Parekattil SJ, Ruggiero GM, Selber JC (eds): Telemicrosurgery: Robot Assisted Microsurgery. Paris: Springer Verlag, 2013

13. Liverneaux P, Nectoux E, Taleb C: The future of robotics in hand surgery. Chir Main 28:278-285, 2009

14. Louie BE, Farivar AS, Aye RW, Vallières E: Early experience with robotic lung resection results in similar operative outcomes and morbidity when compared with matched vid- eo-assisted thoracoscopic surgery cases. Ann Thorac Surg 93:1598-1605, 2012

15. Malessy MJ, Thomeer RT: Evaluation of intercostal to musculocutaneous nerve transfer in reconstructive brachial plexus surgery. J Neurosurg 88:266-271, 1998

16. Mantovani G, Liverneaux P, Garcia JC Jr, Berner SH, Bednar MS, Mohr CJ: Endoscopic exploration and repair of brachial plexus with telerobotic manipulation: a cadaver trial. J Neurosurg 115:659-664, 2011

17. Marulli G, Rea F, Melfi F, Schmid TA, Ismail M, Fanucchi $\mathrm{O}$, et al: Robot-aided thoracoscopic thymectomy for earlystage thymoma: a multicenter European study. J Thorac Cardiovasc Surg 144:1125-1130, 2012

18. Mikami Y, Tajiri Y, Kawano K, Hara Y, Maehara T: [Thoracoscope-assisted intercostal nerve transfer.] J Jpn Soc Surg Hand 24:996-999, 2008 (Jpn)

19. Mikami Y, Tajiri Y, Kawano K, Yamamoto N, Ohtsuka T: [Video-assisted thoracoscopic neurolysis of the intercostal nerve: an experimental study.] J Jpn Soc Surg Hand 23:569-572, 2006 (Jpn)

20. Mikami Y, Yamamoto S, Tajiri K, Maehara T: [Thoracoscope-assisted intercostal nerve transfer.] Jpn J Joint Surg 27:439-446, 2008 (Jpn)

21. Mohammad JA, Hasaniya N, Shenaq S: Endoscopic technique for harvesting the intercostal nerve as a nerve graft: a feasibility preliminary study in cadavers. Plast Reconstr Surg 103:96-100, 1999

22. Nagano A, Ochiai N, Okinaga S: Restoration of elbow flexion in root lesions of brachial plexus injuries. J Hand Surg Am 17:815-821, 1992

23. Naito K, Facca S, Lequint T, Liverneaux PA: The Oberlin procedure for restoration of elbow flexion with the da Vinci robot: four cases. Plast Reconstr Surg 129:707-711, 2012

24. Ochiai N, Mikami Y, Yamamoto S, Nakagawa T, Nagano A: A new technique for mismatched nerve suture in direct intercostal nerve transfers. J Hand Surg [Br] 18:318-319, 1993

25. Panchulidze I, Berner S, Mantovani G, Liverneaux P: Is haptic feedback necessary to microsurgical suturing? Comparative study of $9 / 0$ and $10 / 0$ knot tying operated by 24 surgeons. Hand Surg 16:1-3, 2011

26. Pondaag W, Malessy MJA: Intercostal and pectoral nerve transfers to reinnervate the biceps muscle in obstetric brachial plexus lesions. J Hand Surg Eur 39:647-652, 2014

27. Porto de Melo PM, Garcia JC, Frasson de Souza Montero E, Atik T, Robert EG, Liverneaux PA: Feasibility of an endoscopic approach to the axillary nerve and the nerve branch of the long head of the triceps with the help of the Da Vinci Robot. Chir Main 32:206-209, 2013

28. Ramdhian RM, Bednar M, Mantovani GR, Facca SA, Liverneaux PA: Microsurgery and telemicrosurgery training: a comparative study. J Reconstr Microsurg 27:537-542, 2011

29. Renaud S, Santelmo N, Renaud M, Fleury MC, De Seze J, Tranchant C, et al: Robotic-assisted thymectomy with Da Vinci II versus sternotomy in the surgical treatment of nonthymomatous myasthenia gravis: early results. Rev Neurol (Paris) 169:30-36, 2013

30. Seddon HJ: Nerve grafting. J Bone Joint Surg Br 45:447461, 1963

31. Slutsky DJ: The Art of Microsurgical Hand Reconstruction: A Palette of Procedures. New York: Thieme, 2013

32. Toolabi K, Aminian A, Javid MJ, Mirsharifi R, Rabani A: Minimal access mediastinal surgery: One or two lung ventilation? J Minim Access Surg 5:103-107, 2009

33. van der Meijden OA, Schijven MP: The value of haptic feedback in conventional and robot-assisted minimal invasive surgery and virtual reality training: a current review. Surg Endosc 23:1180-1190, 2009

34. Wahegaonkar AL, Doi K, Hattori Y, Addosooki AI: Technique of intercostal nerve harvest and transfer for various 
neurotization procedures in brachial plexus injuries. Tech Hand Up Extrem Surg 11:184-194, 2007

35. Waikakul S, Wongtragul S, Vanadurongwan V: Restoration of elbow flexion in brachial plexus avulsion injury: comparing spinal accessory nerve transfer with intercostal nerve transfer. J Hand Surg Am 24:571-577, 1999

36. Weksler B, Sharma P, Moudgill N, Chojnacki KA, Rosato EL: Robot-assisted minimally invasive esophagectomy is equivalent to thoracoscopic minimally invasive esophagectomy. Dis Esophagus 25:403-409, 2012

37. Xu WD, Gu YD, Xu JG, Tan LJ: Full-length phrenic nerve transfer by means of video-assisted thoracic surgery in treating brachial plexus avulsion injury. Plast Reconstr Surg 110:104-111, 2002

\section{Author Contributions}

Conception and design: Liverneaux, Santelmo. Acquisition of data: Liverneaux, Miyamoto, Serradori, Facca. Analysis and interpretation of data: Liverneaux, Miyamoto, Facca. Drafting the article: Liverneaux, Miyamoto. Critically revising the article:
Liverneaux, Mikami, Selber. Reviewed submitted version of manuscript: Liverneaux. Approved the final version of the manuscript on behalf of all authors: Liverneaux. Statistical analysis: Liverneaux, Miyamoto. Administrative/technical/material support: Liverneaux. Study supervision: Liverneaux.

\section{Supplemental Information Videos}

Video 1, Media Player. http://mfile.akamai.com/21490/wmv/ digitalwbc.download.akamai.com/21492/wm.digitalsource-naregional/jns14-603_video_1.asx.

Video 1, Quicktime. http://mfile.akamai.com/21488/mov/ digitalwbc.download.akamai.com/21492/qt.digitalsource-global/ jns14-603_video_1.mov.

\section{Correspondence}

Philippe Liverneaux, Hôpitaux Universitaires de Strasbourg, 10 avenue Achille Baumann, Illkirch 67403, France. email: liverneaux.philippe@orange.fr. 